\title{
Iranian Natural Red Soil and Its Modified Form with EDTA for Removal of Phosphorous from Aqueous Solution
}

\author{
Mansur Zarrabi', Reza Ali Falahzadeh², Mohammad Shakak ${ }^{3,4}$, Mojtaba Sadeghnia5, \\ Ahmad Fattahi ${ }^{5}$, Shahram Sadeghi ${ }^{3,4^{*}}$ \\ ${ }^{1}$ Faculty of Health, Students' Research Committee, Shahid Beheshti University of Medical Sciences, Tehran, Iran \\ ${ }^{2}$ Department of Environmental Health Engineering, School of Public Health, Shahid Sadoughi University of \\ Medical Sciences, Yazd, Iran \\ ${ }^{3}$ Student Research Committee, Kurdistan University of Medical Sciences, Sanandaj, Iran \\ ${ }^{4}$ Department of Environmental Health Engineering, School of Public Health, Kurdistan University of Medical \\ Sciences, Sanandaj, Iran \\ ${ }^{5}$ Department of Occupational Health Engineering, School of Public Health, Shahid Sadoughi University of \\ Medical Sciences, Yazd, Iran \\ Email: ${ }^{*}$ shahram.snna@yahoo.com
}

Received 5 October 2015; accepted 21 October 2015; published 26 October 2015

Copyright (C) 2015 by authors and OALib.

This work is licensed under the Creative Commons Attribution International License (CC BY).

http://creativecommons.org/licenses/by/4.0/

(c) (i) Open Access

\section{Abstract}

In water, removing excessive amounts of phosphorus is necessary to prevent eutrophication. Phosphorus can be seen usually in the form of organic phosphate and inorganic phosphate in surface waters and wastewater. Phosphates are one of the main materials of many factories and industries and it is a major factor in the development and control of water resources eutrophication. The purpose of this study is the survey of potential use of red Pumice Stone of western Azerbaijan region and its Modified form by EDTA for remove phosphate from aqueous solutions. In this study, we used the red soil of western Azerbaijan region to remove phosphorus from simulated solutions. All experiments were performed in a batch system. The effect of various parameters such as reaction time, initial concentration of phosphorus, $\mathrm{pH}$ and dissolved amount of adsorbent on the removal efficiency of the process was studied. The results showed that the removal efficiency increased with increasing contact time, adsorbent dose and initial concentration of phosphate ions. The highest efficiency occurred in 150 minutes of reaction time with $10 \mathrm{~g} / \mathrm{L}$ adsorbent and $50 \mathrm{mg} /$ $\mathrm{L}$ dissolved phosphate concentration at the $\mathrm{pH}$ 5. In optimal conditions, using of raw sorbent removed about 65 percent of the phosphate ion and with the modified inorganic Pumice removed about 78 percent of phosphorus ions. In general, results showed that raw red soil was able to remove phosphate ions in the acceptable range due to high calcium levels in soil context. And its removing ability will increase significantly if modified by EDTA.

${ }^{*}$ Corresponding author.

How to cite this paper: Zarrabi, M., Falahzadeh, R.A., Shakak, M., Sadeghnia, M., Fattahi, A. and Sadeghi, S. (2015) Iranian Natural Red Soil and Its Modified Form with EDTA for Removal of Phosphorous from Aqueous Solution. Open Access Library Journal, 2: e1856. http://dx.doi.org/10.4236/oalib.1101856 


\title{
Keywords
}

\section{EDTA, Red Soil, Phosphorus, Batch System}

\author{
Subject Areas: Environmental Chemistry, Environmental Sciences
}

\section{Introduction}

Phosphorus as phosphate can be found in aqueous solutions. There are various forms of phosphate containing orthophosphate and condensed phosphates (pyrophosphate, metaphosphate and polyphosphate). These compounds may be found in solid or liquid form, and it can even act as a component of plant or animal tissues [1]. Phosphates pass the photosynthesis and decomposition such as nitrogen. Phosphates are commonly used to replace or to supplement the chemical fertilizers on arable land. Phosphate can be created from soil contamination [2]. It can be leached from arable land and penetrate into surface waters. However, the tendency of soils to phosphate absorption limits the movement of it in soil moisture and groundwater, due to the increased soil erosion appearing in surface water [2] [3].

Municipal wastewater is the other main source of phosphate for entrance into surface waters. Polymeric phosphate detergents are widely used in detergent structure. Organic phosphates are components of body wastes and food debris. Other sources include industrial wastewater that phosphate compounds are used in industries propose such as treatment water unit for using in the boilers. Although phosphate is not toxic and has no direct threat to humans, phosphate compound are indirect threat for water quality. When the amount of phosphate increases, the growth of aquatic plants has increased too. So, dissolved oxygen decreases as the result and cause of water taste and odor [4] [5]. The phosphate can cause problems in water treatment processes. $0.2 \mathrm{mg} / \mathrm{L}$ of Phosphate concentration can disturb the turbidity coagulation [6]. The standard amount of phosphate in drinking water is $0.2 \mathrm{mg} / \mathrm{L}$ and for wastewater discharge into surface water it is $6 \mathrm{mg} / \mathrm{L}$. Chemical phosphorus removal can be done by precipitation with divalent metal cations. Phosphates are insoluble depending on degrees of cations. The costs of chemical phosphorus removal are almost half of the cost of biological method removal. The cost of used materials is the major problem of chemical phosphorus removal [6].

\section{Materials and Methods}

This is a Basic-Applied study that done in a batch system in wastewater laboratory of health faculty of Alborz university. The samples studied in this research are the synthetic samples of phosphate aqueous solutions that mad in the laboratory. This study was conducted to investigate the potential use of red Pumice Stone of western Azerbaijan region (in Iran) and its modified form by EDTA for remove phosphate from aqueous solutions. Since in this study was evaluated 4 absorbents, a contaminant, in 6 different times, five different concentrations of the contaminant and adsorbent, and $5 \mathrm{pH}$, and the test repeated twice for each parameter, So the total number of samples equal to 168 . The effect of various parameters were examined on the removal efficiency, the parameters such as initial concentration of phosphate ions (10 - 50 mg/L), Initial pH (3 - 11), Reaction time (15 - $200 \mathrm{~min})$, And the amount of absorbent $(2-10 \mathrm{~g} / \mathrm{L})$. To investigate the effect of the above parameters, one parameter was changed and the other parameters were held constant. It should also be noted that the amount of phosphate ions was measured with a spectrophotometer at the maximum absorption wavelength of $470 \mathrm{~nm}$, by using a UV/VIS spectrophotometer (Model DR5000).

\subsection{Methods of Preparation and Modification of Raw Absorbent}

At first the used absorbent washed properly with ion-free water to remove impurities and dust. Washed absorbent dried for $24 \mathrm{~h}$ at $60^{\circ} \mathrm{C}$ for remove the water in the pores. Then for $24 \mathrm{~h}$ at room temperature contacted with EDTA were to be modified. After this time, the red soil was washed several times with distilled water to remove excess EDTA. After washing thoroughly, prepared absorbent dried at $60^{\circ} \mathrm{C}$ to be used for adsorption experiments. 


\subsection{Investigation Method of Initial Concentration Effect of Phosphate Ions on the Efficiency of the Removal Process}

To study the effect of initial concentration of phosphate ions on the efficiency of the removal process, dissolved phosphorus were prepared in 10, 20,30, 40 and $50 \mathrm{mg} / \mathrm{L}$ concentration. Then $100 \mathrm{cc}$ of phosphate reagent was added to 6 Erlenmeyer Flask and $\mathrm{pH}$ was adjusted on 5 . After adding $1 \mathrm{~g} / \mathrm{L}$ of the absorbent in each of the Erlenmeyer flasks, shaker device was switched on with $150 \mathrm{rpm}$ and mixed the solution for 1 hour and then the absorbent on the Erlenmeyer flasks was removed by filtration. And thus the residual concentration of phosphate ions was determined in solution by using absorption spectrophotometer. It should be noted that in all parameters investigation used as a control sample that containing distilled water.

\subsection{Investigation Method of the Effect of Contact Time on the Removal Efficiency}

To evaluate the effect of contact time on the removal efficiency the phosphorus solution was prepared in 20 $\mathrm{mg} / \mathrm{L}$ concentration (optimal initial concentration that set in the previous step). Then $100 \mathrm{cc}$ of phosphate reagent was added to 7 Erlenmeyer Flask and $\mathrm{pH}$ was adjusted on 5. After adding $1 \mathrm{~g} / \mathrm{L}$ of the absorbent in each of the Erlenmeyer flasks, shaker device was switched on with $150 \mathrm{rpm}$ and mixed the solution until 150 minutes. At this point was taken a sample in intervals time 15, 30, 45, 60, 120 and $150 \mathrm{~min}$. then the absorbent was removed from the Erlenmeyer Flask by filtration and residual phosphorus concentrations were determined by absorption spectrophotometer. Thus, detected the appropriate contact time (optimal contact time).

\subsection{Investigation Method of the Effect of Absorbent Amount on the Removal Efficiency}

To evaluate the effect of absorbent amount on the removal efficiency of the phosphorus solution was prepared in $20 \mathrm{mg} / \mathrm{L}$ concentration. Then $100 \mathrm{cc}$ of phosphate reagent was added to 6 Erlenmeyer Flask and $\mathrm{pH}$ was adjusted on 5. on the next step 2, 4, 6, 8 and $10 \mathrm{~g} / \mathrm{L}$ of absorbent were added to each of Erlenmeyer Flask. After adding absorbent, the Erlenmeyer Flasks put on the shaker and were mixed with the 150 rpm for 150 minutes. then the absorbent was removed from the Erlenmeyer Flask by filtration and residual phosphorus concentrations were determined by absorption spectrophotometer, So the optimum absorbent dose was determined.

\subsection{Investigation Method of the Effect of $\mathrm{pH}$ on the Removal Efficiency}

To evaluate the effect of $\mathrm{pH}$ on the removal efficiency of the phosphorus solution was prepared in $20 \mathrm{mg} / \mathrm{L}$ concentration. Then $100 \mathrm{cc}$ of phosphate reagent was added to 6 Erlenmeyer Flask and the $\mathrm{pH}$ of each Erlenmeyer Flasks were adjusted respectively on 3, 5, 7,9 and 11. To adjust the $\mathrm{pH}$ used of soda and sulfuric acid by 1 normality. After this stage, and after adding $10 \mathrm{~g} / \mathrm{L}$ of absorbent, the Erlenmeyer Flask put on the shaker and were mixed with the $150 \mathrm{rpm}$ for 150 minutes and then the absorbent was removed from the Erlenmeyer Flask by filtration and residual phosphorus concentrations were determined by absorption spectrophotometer, So the optimum $\mathrm{pH}$ was determined.

\section{Results}

\subsection{Determine the Characteristics of Absorbent}

Fourier transform infrared spectroscopy (FTIR) of used absorbents is shown in Figure 1.

\subsection{The Effect of Various Parameters on Phosphorus Removal}

\subsubsection{The Effect of Contact Time on the Removal Efficiency}

The results showed that phosphorus removal efficiency increases with increasing contact time. The removal rate are $45 \%$ for raw red soil absorbent in 60 min contact time. aw red soil was determined that removal of contact time of 60 minutes is equal to $45 \%$, but by 150 minutes contact time, $60 \%$ of phosphorus concentration were eliminated (Figure 2(a)). The removal rate of red soil absorbent amended by EDTA in a 15-minute contact time was 40 percent. By increasing the contact time to 150 minutes the average removal rate was 72 percent (Figure 2(b)). 


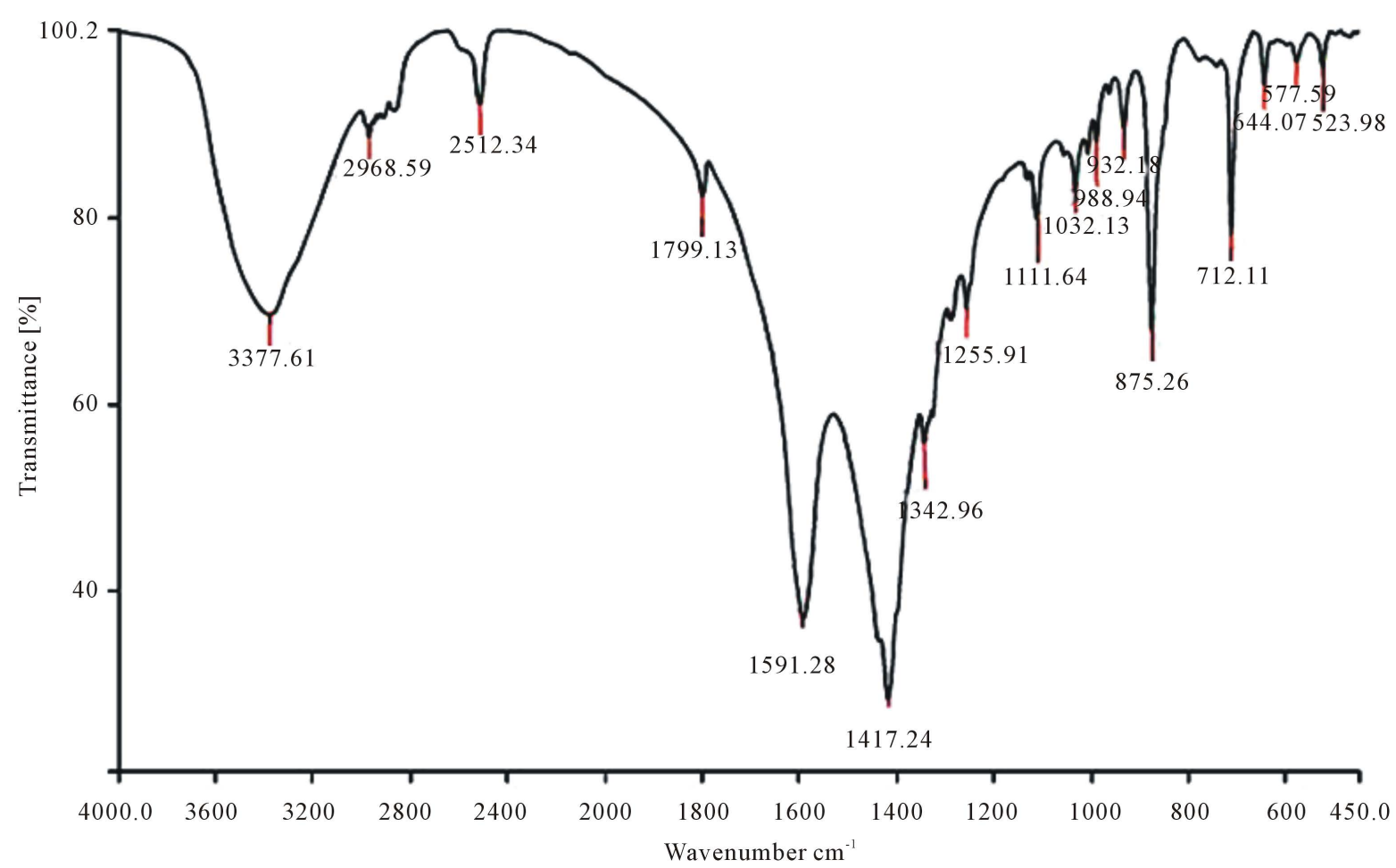

(a)

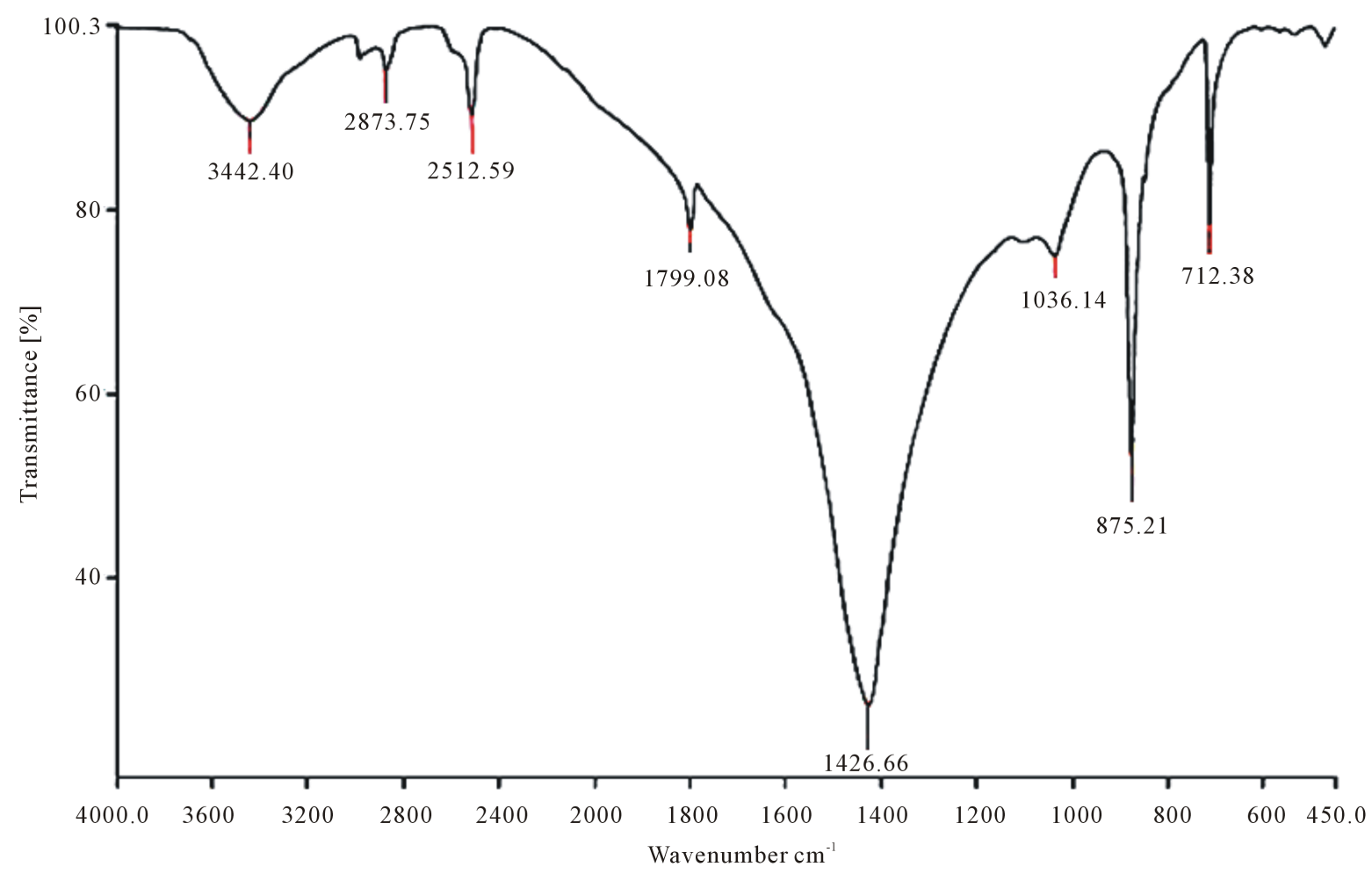

(b)

Figure 1. Fourier transform infrared spectroscopy (FTIR) of raw red Pumice Stone (a) and its Modified form by EDTA (b) before phosphorous absorption. 


\subsubsection{Effect of Initial Phosphorus Concentration on the Efficiency of Removal Process}

The results of the effect of initial concentration of phosphate ions showed that the removal efficiency increased by increasing initial concentration of phosphate ion. The removal efficiency increase from 42 percent to 56 percent by increasing concentration of phosphate from $10 \mathrm{mg} / \mathrm{L}$ to $20 \mathrm{mg} / \mathrm{L}$ (Figure 3(a)). and about the red soil that amended with EDTA, removal efficiency directly associated by increasing in concentration. As the removal of phosphorous ions average was $80.35 \%$ in $50 \mathrm{mg} / \mathrm{L}$ initial concentration (Figure 3(b)).

\subsubsection{Effect of Adsorbent Dose on the Removal Efficiency}

The results showed that by increasing the amount of absorbent dose the effect removal efficiency will be increased. In the raw red soil with increasing adsorbent dosage to $10 \mathrm{~g} / \mathrm{L}$, the removal rate was $65.4 \%$ (Figure $4(a))$. But with the increase in adsorbent dose to $10 \mathrm{mg} / \mathrm{L}$ in the red soil that amended with EDTA, the removal efficiency was $73 \%$ (Figure 4(b)).

\subsubsection{Effect of $\mathrm{pH}$ on the Removal Efficiency}

the present study showed that with increasing solution $\mathrm{pH}$ from 2 to 6 , the removal efficiency increases and in the range 5 to 6 the removal efficiency was maximum. With increasing $\mathrm{pH}$ from 6 to 10 , the removal efficiency decreased. In this study, the best removal efficiency was in $\mathrm{pH} 5$, which for raw red soil equal to $53 \%$ (Figure 5(a)) and $61 \%$ for the red soil that amended with EDTA (Figure 5(b)).

\section{Discussion}

Phosphorus removal efficiency increased with increasing contact time and reach to equilibrium point in 150

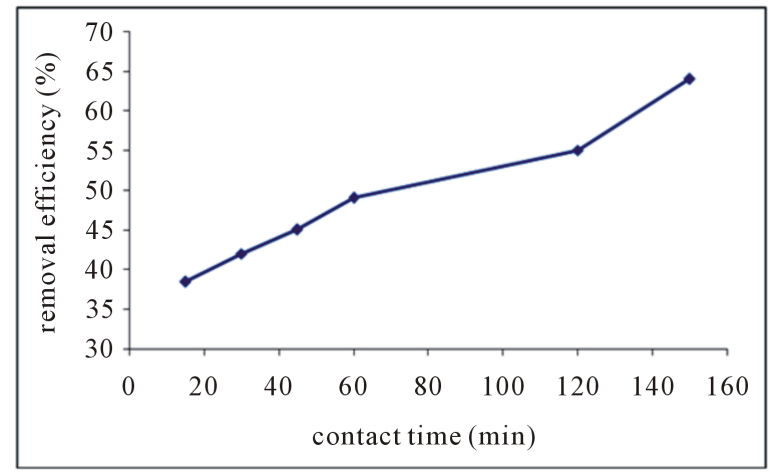

(a)

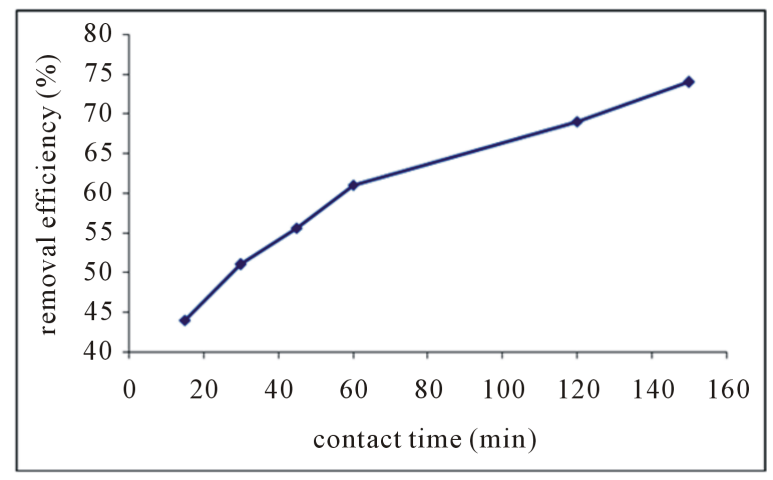

(b)

Figure 2. The effect of contact time on the removal efficiency of phosphorus by the absorbent, raw red soil (a) and modified absorbent (b).

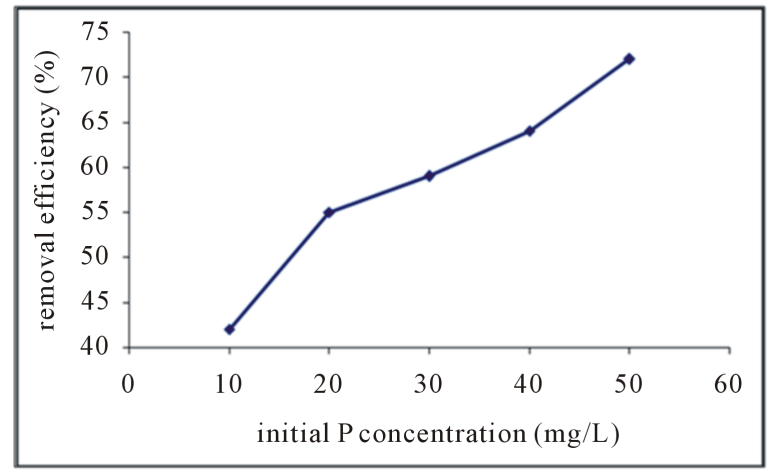

(a)

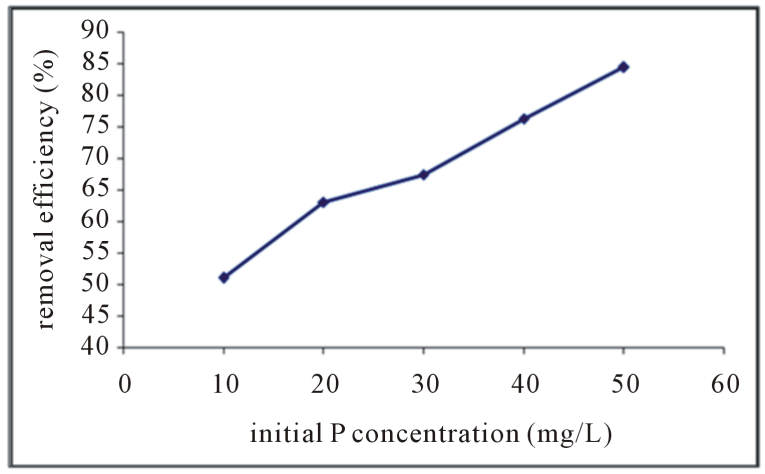

(b)

Figure 3. The effect of initial phosphorus concentration on the removal efficiency of phosphorus by the absorbent, raw red soil (a) and modified absorbent (b). 


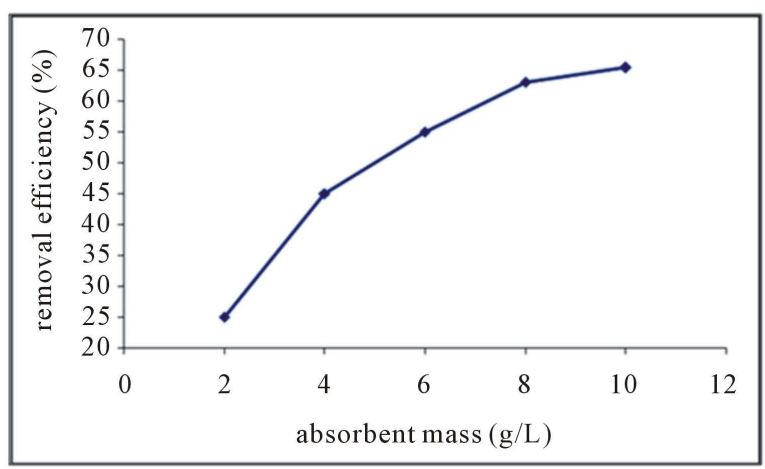

(a)

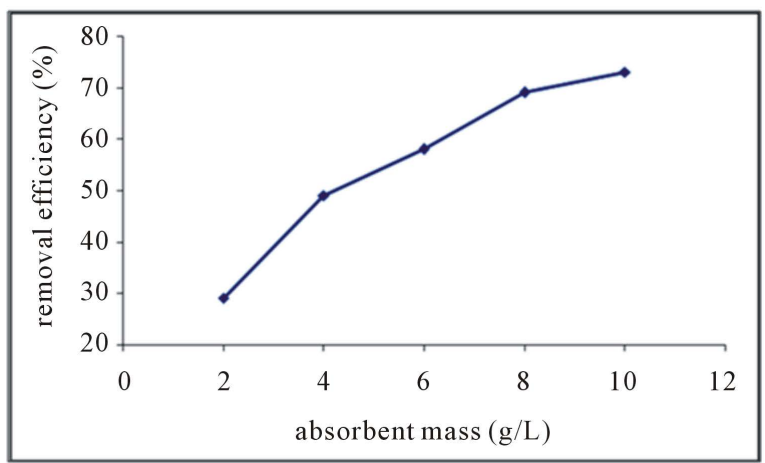

(b)

Figure 4. The effect of adsorbent dose on the removal efficiency of phosphorus by the absorbent, raw red soil (a) and modified absorbent (b).

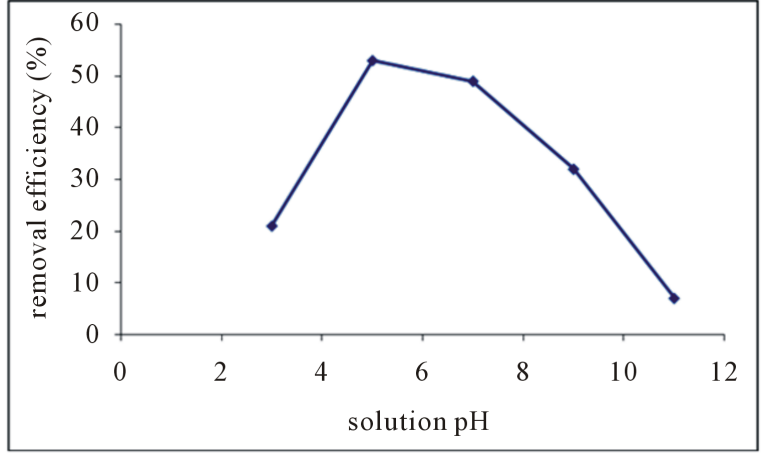

(a)

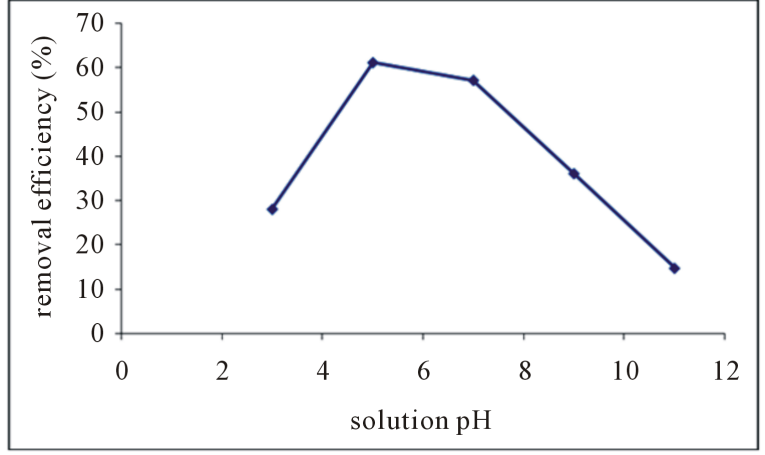

(b)

Figure 5. The effect of solution $\mathrm{pH}$ on the removal efficiency of phosphorus by the absorbent, raw red soil (a) and modified absorbent (b).

minutes. So that the maximum amount of phosphorus removal for red soil amended by EDTA was $72 \%$. Thus, it was shown that the modified absorbent performance ratio is more than raw absorbent. The raw soil amended by EDTA reduces the saturation time and will increase the subsequent removal. In a study that conducted by Liang-guo, used of Bentonite soil amended with Aluminum hydroxide, Iron hydroxide and Iron hydroxide-aluminum for phosphorus removal, In this study, equilibrium time was achieved in approximately 200 minutes and amount of absorbent dose was $4 \mathrm{~g} / \mathrm{L}$ and Initial phosphorus concentration was $20 \mathrm{mg} / \mathrm{L}$. And for three adsorbents the removal rate was $76 \%, 79 \%$ and $82 \%$ after 200 minutes contact time [7]. So their result consistent with the present results. In another study, Keetall used of rawashes and modified form for remove phosphorus. Phosphorus concentrations was $70 \mathrm{mg} / \mathrm{L}$ and absorbent dosage was chosen $10 \mathrm{~g} / \mathrm{L}$. Results showed that unmodified ash flight were capable to remove $10 \mathrm{mg} / \mathrm{L}$ of phosphorus concentrations in 100 minutes while the modified Ash was able to escape $63 \mathrm{mg} / \mathrm{L}$ at the same time. The remarkable point was that contrary to results of present study increasing contact time did not show significant effect in increasing removal efficiency [8]. A significant increase was shown in the efficiency of the process by increasing in phosphorus initial concentrations. Because increase the concentration pollutants increases the concentration gradient of the solution into the absorbent in aquatic environment. So the removal process will be increase. In the present study, the increase in initial concentration of phosphorus was enhanced removal rate of it. The removal rate of amended soils was higher than raw soil. Similar results have been observed on absorbent that made of coal ash, red mud and wheat waste [9]-[11].

Increasing the adsorbent dose increases the phosphorus removal rate and the phosphorus removal efficiency for amended soil was better than raw soil. This increased efficiency of removal rate related to adsorbent surface that increased by increasing absorbent dosage. Similar results were reported by Paola [12].

The solution $\mathrm{pH}$ is an important factor in the environmental pollutants removing process. In a side the solu- 
tion $\mathrm{pH}$ affect on the ionic species of target pollutants and on the other side change the surface charge of adsorbent by hydrogen ions and hydroxyl bombardment and will affect to removal process [13]-[15]. It can be considered in phosphorus case too. Firstly, adsorbent surface covered with hydrogen positive ions in acidic environments and negative ions in alkali environment and adsorbent surface will saturate by hydroxyl. It can be stated that the second step is the effects of solution $\mathrm{pH}$ on phosphorus species in acidic and alkaline conditions, In the acidic conditions ( $\mathrm{pH} 4$ and below), dominant species of phosphorus ions are $\mathrm{H} 3 \mathrm{PO} 4$ and $\mathrm{H} 2 \mathrm{PO} 4$ - that will attached weakly to the surface of absorbent and on the alkaline conditions (higher than $\mathrm{pH} 8$ ) dominant species are PO4-3 of phosphorus ions. In neutral conditions ( $\mathrm{pH}$ from 5 to 8 ) dominant species will be HPO4-2 ions that will attached to absorbent [16] [17]. In the present study showed that removal efficiency increases with increasing solution $\mathrm{pH}$ from 2 to 6 , the reason is that in acidic conditions $(\mathrm{pH}=2)$ dominant species of phosphoric acid are (H3PO4 and $\mathrm{H} 2 \mathrm{PO} 4-i o n s)$ which reduces the efficiency of removal process. By increasing the pH to about $5-7$ dominant ions are HPO4-2 which cause a strong link with the absorbent and thus the removal efficiency in this range of $\mathrm{pH}(\mathrm{pH}=5$ in this study) reaches its maximum rate. Also the removal efficiency decreased with increasing $\mathrm{pH}$ from 6 to 10 . This is due to the presence of PO4-3ions and dominance of hydroxyl negative ions that compete with phosphate ions to adsorb onto the absorbent and reduces the efficiency of process. In this study, the best removal efficiency was at $\mathrm{pH} 5$, which for raw red soil equal to $53 \%$ and $61 \%$ for the red soil that amended with EDTA. In most studies that have been done, the maximum phosphorus removal has been reported in the range of $\mathrm{pH} 5$ to 7.

\section{Conclusions}

The results show that raw red soil and amended form of it have a remarkable ability to remove phosphate ions. The followings are recommended for further study:

1) Converting the raw red soil to granular form and improving the structure for increasing removal efficiency;

2) Evaluating the performance of this soil to the removal of other ions;

3) Enhancing the adjustment methods and use of other substances for modification and enhancement of the removal efficiency.

\section{References}

[1] Samadi, M.T., Ghadiri, K., Hadi, M. and Beik mohammadi, M. (2010) Performance of Simple Nano Zeolite Y and Modified Nano Zeolite Y in Phosphor Removal from Aqueous Solutions. Journal of Health \& Environment, 3, 27-36.

[2] Samarghandi, M.R., Noori Sepehr, M., Zarabi, M. and Borji, S. (2013) Determination of Thermodynamic and Kinetic Parameters During Sorption of Phosphorous by Weakly Anion Exchanger. Journal of Water and Wastewater, 3, 2-11.

[3] Yari, M. (2008) Performance of MBBR in the Treatment of Combined Municipal and Industrial Wastewater, a Case Study: Mashhad Wastewater Treatment Plant of Parkandabad. Journal of Water and Wastewater, 65, 38-46.

[4] Pinar, A.K. and Olgun, G. (2010) Preparation of Quaternized Dimethylaminoethyl Methacrylate Grafted Nonwoven Fabric for the Removal of Phosphate. Radiation Physics and Chemistry, 79, 233-237.

[5] Agnieszka, R. (2010) Long-Term Phosphate Removal by the Calcium-Silicate Material Polonite in Wastewater Filtration Systems. Chemosphere, 79, 659-664.

[6] Lawrence Reiter, H.F. and Charles Groat, C.M. (2004) National Academy of Sciences. From Source Water to Drinking Water; Coussens: Workshop Summary.

[7] Yan, L.G., Xu, Y.Y., Xin, X.D., Wei, Q. and Du, B. (2010) Adsorption of Phosphate from Aqueous Solution by Hydroxy-Aluminum, Hydroxy-Iron and Hydroxy-Iron-Aluminum Pillared Bentonites. Journal of Hazardous Materials, 179, 244-250.

[8] Xu, K., Deng, T., Liu, J.T. and Peng, W.G. (2010) Study on the Phosphate Removal from Aqueous Solution Using Modified Fly Ash. Fuel, 89, 3668-3674. http://dx.doi.org/10.1016/j.fuel.2010.07.034

[9] Xu, X., Gao, B.-Y., Yue, Q.-Y., Zhong, Q.-Q. and Zhan, X. (2010) Preparation, Characterization of Wheat Residue Based Anion Exchangers and Its Utilization for the Phosphate Removal from Aqueous Solution. Carbohydrate Polymers, 82, 1212-1218. http://dx.doi.org/10.1016/j.carbpol.2010.06.053

[10] Yue, Q.Y., Zhao, Y.Q., Li, Q., Li, W.H., Gao, B.Y., Han, S.X., Qi, Y.F. and Yu, H. (2010) Research on the Characteristics of Red Mud Granular Adsorbents (RMGA) for Phosphate Removal. Journal of Hazardous Materials, 176, 741748.

[11] Yu, Y., Wu, R.P. and Clark, M. (2010) Phosphate Removal by Hydrothermally Modified Fumed Silica and Pulverized 
Oyster Shell. Journal of Colloid and Interface Science, 350, 538-543.

[12] Paola, C.M.S., Giovanni, G. and Salvatore, D. (2010) Influence of the pH on the Accumulation of Phosphate by Red Mud. Journal of Hazardous Materials, 182, 266-272.

[13] Miltiadis, Z., Areti, G., Panagiota, S., Yiannis, D. and Ierotheos, Z. (2012) Removal of Phosphate from Natural Waters Using Innovative Modified Bentonites. Applied Clay Science, 62-63, 101-106.

[14] Liu, T., Wu, K. and Zeng, L.H. (2012) Removal of Phosphorus by a Composite Metal Oxide Adsorbent Derived from Manganese Ore Tailings. Journal of Hazardous Materials, 217, 29-35. http://dx.doi.org/10.1016/j.jhazmat.2012.01.019

[15] Salah, J., Rafik, B.H., Ahmed, H.H. and Latifa, B. (2011) Adsorption Characteristics of Phosphorus from Aqueous Solutions onto Phosphatemine Wastes. Chemical Engineering Journal, 169, 157-165. http://dx.doi.org/10.1016/j.cej.2011.02.076

[16] Zhang, J.D., Shen, Z.M., Shan, W.P., Chen, Z.Y., Mei, Z.J., Lei, Y.M. and Wang, W.H. (2010) Adsorption Behavior of Phosphate on Lanthanum (III) Doped Mesoporous Silicates Material. Journal of Environmental Sciences, 22, $507-511$. http://dx.doi.org/10.1016/S1001-0742(09)60141-8

[17] Xu, K., Deng, T., Liu, J.T. and Peng, W.G. (2010) Study on the Phosphate Removal from Aqueous Solution Using Modified Fly Ash. Fuel, 193, 123-133. http://dx.doi.org/10.1016/j.fuel.2010.07.034 